\title{
DISERTACIONES
}

ESTUDIOS

Anuario electrónico de estudios en Comunicación Social

ISSN: $1856-9536$

Doi: dx.doi.org/10.12804/disertaciones.09.02.2016.06

Volumen 9, Número 2 / julio-diciembre 2016

Versión PDF para imprimir desde

http://revistas.urosario.edu.co/index.php/disertaciones

Para citar este artículo: Vega, P. (2016). La investigación sobre comunicación en Centroamérica (1980-

2015). Anuario Electrónico de Estudios en Comunicación Social “Disertaciones”, 9(2), 117-138. Doi: dx.doi.

org/10.12804/disertaciones.09.02.2016.06

\section{LA INVESTIGACIÓN SOBRE COMUNICACIÓN EN CENTROAMÉRICA (1980-2015)}

Communication Research in Central America (1980-2015)

A investigação sobre comunicação na América Central (1980-2015)

Vega Jiménez, Patricia. Universidad de Costa Rica (Costa Rica)

patricia.vega@ucr.ac.cr

Fecha de recibido: 14 de octubre de 2015

Fecha de aprobado: 09 de mayo de 2016

\section{RESUMEN}

El objetivo de este trabajo es analizar los textos académicos que estudian la producción científica sobre comunicación realizada en instituciones académicas centroamericanas desde 1980 hasta 2015. Se recopilaron 242 documentos cuyo análisis evidencia el interés de las y los académicas/os por investigar la comunicación en muy diversos aspectos. Los documentos demuestran una vinculación de las investigaciones académicas con la coyuntura y el contexto de cada país y de la región en general. Los estudios que se publicaron durante la década del ochenta, por ejemplo, refieren a la comunicación y al conflicto centroamericano; en los años noventa, al papel de la comunicación en la construcción de la democracia; y desde el inicio del siglo xxı hay un desvelo por las telecomunicaciones y las tecnologías de la información y la comunicación. La enseñanza de la comunicación en Centro América data, en términos generales, de la década del ochenta, a excepción de Guatemala y Costa Rica. Esto favorece la investigación y la divulgación de estudios referentes a la comunicación.

Palabras clave: comunicación, investigación, periodismo, América Central. 


\section{DISERTACIONES}

ESTUDIOS

Anuario electrónico de estudios en Comunicación Social

ISSN: 1856-9536

Doi: dx.doi.org/10.12804/disertaciones.09.02.2016.06

Volumen 9, Número 2 / julio-diciembre 2016

Versión PDF para imprimir desde

http://revistas.urosario.edu.co/index.php/disertaciones

\section{ABSTRACT}

The purpose of this essay is to analyse academic texts that study the scientific production on communication in Central American, academic institutions between 1980 and 2015. We collected 242 documents whose analysis demonstrates the interest of the academics to investigate communications in different ways. The documents show a relationship between the academic research with the situation and context of each country and the region in general. Studies published during the 1980's, for example, refer to the communication and the Central American conflict. In the 1990 s, the role of communication in the construction of democracy, and from the beginning of the $21^{\text {st }}$ century there is a new interest in telecommunications and Information and Communication Technologies (ICT). Teaching of communications in Central America began until the decade of 1980, with the exception of Guatemala and Costa Rica. This favoured the research and dissemination of studies concerning communication.

Keywords: Communication, research, journalism, Central America.

\section{RESUMO}

O objetivo deste trabalho é analisar os textos acadêmicos que estudam a produção científica sobre comunicação realizada em instituições acadêmicas centro-americanas desde 1980 até 2015. Recopilaram-se 242 documentos cujo análise evidencia o interesse dos acadêmicos por investigar a comunicação em muitos diversos aspectos. Os documentos demostram uma vinculação das investigações acadêmicas com a conjuntura e o contexto de cada país e da região em geral. Os estudos que se publicaram durante a década de 1980, por exemplo, referem à comunicação e ao conflito centro-americano; nos anos 90, o papel da comunicação na construção da democracia; e desde o início do século XXI há um desvelo pelas telecomunicações e as tecnologias da informação e a comunicação. $O$ ensino da comunicação na América Central data em termos gerais da década de 1980, a exceção da Guatemala e a Costa Rica. Isto favorece a investigação e a divulgação de estudos referentes à comunicação.

Palavras-chave: Comunicação, investigação, jornalismo, América Central.

\section{Introducción}

Las diversas áreas de la comunicación (periodismo, publicidad, relaciones públicas, comunicación organizacional, comunicación mediática, etc.) han sido objeto de reflexión académica en el territorio que conforma Centro América, a pesar de ser una región tan convulsa y cambiante, o quizá por eso. Aunque la enseñanza de la comunicación en las universidades data de finales de los años sesenta y la mayoría de las carreras empezaron a impartirse en el 


\section{DISERTACIONES}

ESTUDIOS

Anuario electrónico de estudios en Comunicación Social

ISSN: 1856-9536

Doi: dx.doi.org/10.12804/disertaciones.09.02.2016.06

Volumen 9, Número 2 / julio-diciembre 2016

Versión PDF para imprimir desde

http://revistas.urosario.edu.co/index.php/disertaciones

ocaso de los años ochenta ${ }^{1}$, los estudiosos de la comunicación se han ocupado de su desarrollo teórico, metodológico, práctico y específicamente hay aportes reveladores en la historia de la comunicación, el análisis de género vinculado con la comunicación, la libertad de expresión y el derecho a la información pública, las telecomunicaciones y el impacto y usabilidad de las tecnologías de la información y la comunicación en las sociedades centroamericanas. Ciertamente, hay diferencias importantes en cada uno de los países en la cantidad y en la calidad de las reflexiones. En algunos años aumenta el número significativamente, mientras en otros es en extremo reducido. Las temáticas también varían con los años y en los diversos contextos y coyunturas nacionales y regionales.

Martín Barbero (1980) explica los retos de la investigación en Comunicación en América Latina asiéndose de tres elementos: las tácticas de dominio en el campo de la investigación; las nuevas tecnologías de la comunicación presentadas y recibidas, como matriz de un nuevo modelo social y de seudoutopía; y, finalmente, la articulación económico-política de las comunicaciones con el proceso social global. En 1999, Raúl Fuentes interpreta las inercias y las iniciativas que predominan en el campo de la comunicación en los años noventa y hace propuestas de reformulación estratégica en el campo de la historia, en el científico y en la construcción comunitaria del futuro. Por su parte, Esteinou (1998) establece cuatro etapas en la evolución de la investigación sobre comunicación en América Latina: "la fase clásico humanista (1930-1945), la fase científico-técnica (1946-1965), la fase crítico reflexiva (1966-1985), la fase de apertura conceptual (1986-1990), y la fase de la comunicación-mercado (1990-2000)" (p. 1).

El análisis de lo publicado en la región, en materia de comunicación, es un asunto poco estudiado. En 2013 se realizó un diagnóstico general del estado del conocimiento en la investigación en comunicación en Centroamérica, para conocer los temas que han sido abordados y las influencias coyunturales que han favorecido unos y otros, con el propósito de "reflexionar en torno al avance y retos de este tema y la importancia de efectuar esta tarea, en procura de buscar alternativas sobre la participación de la comunicación social en el desarrollo de las comunidades centroamericanas" (Vega, 2013, p. 987). En general, se detectó una tendencia al incremento del número de publicaciones referentes a la comunicación a inicios del siglo xxı, un crecimiento que coincide con el avance en las tecnologías al servicio de la academia y con el inicio y fortalecimiento de un periodo de paz tras la cruenta guerra que azotó a Centroamérica desde inicios de 1970, y que conforma el necesario contexto para entender el desarrollo de la investigación sobre comunicación en la región.

\section{Centroamérica convulsa: el contexto}

La guerra involucró a toda la región y, tras los procesos de paz, decantó un espacio de violencia generalizada. Múltiples factores desataron el conflicto. Por una parte, ni el modelo primario de exportación, que dominó las estructuras socioeconómicas de 1821 a 1950, ni el proceso de industrialización por sustitución de importaciones, que se expande de 1950 a 1989, fueron capaces de alivianar la pobreza y satisfacer las necesidades de la población.

Con excepción de Costa Rica, a finales de los años setenta prevalecieron los regímenes autoritarios. En Nicaragua, la familia Somoza detentaba el poder desde 1936, lo que provocaba un malestar social en la burguesía, la Iglesia Católica y los sectores populares. De estos últimos, surge en 1963 el Frente Sandinista de Liberación Nacional

1 En Centroamérica hay 54 Escuelas que forman comunicadores. En Guatemala, El Salvador y Nicaragua hay 10 en cada uno, 12 en Costa Rica, 5 en Honduras y 8 en Panamá.

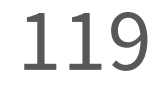




\section{DISERTACIONES}

Estudos

Anuario electrónico de estudios en Comunicación Social

ISSN: $1856-9536$

Doi: dx.doi.org/10.12804/disertaciones.09.02.2016.06

Volumen 9, Número 2 / julio-diciembre 2016

Versión PDF para imprimir desde

http://revistas.urosario.edu.co/index.php/disertaciones

(FSLN) que, tras una cruenta guerra de guerrillas, derroca a Somoza en 1979 y se instaura un régimen, liderado por Daniel Ortega, que no tardó en declarar su adhesión y simpatía por la propuesta socialista liderada entonces, en el contexto de la Guerra Fría, por la Unión de Repúblicas Socialistas Soviéticas. La reacción de Estados Unidos no se hizo esperar y apadrinó a los sectores opuestos al régimen de Daniel Ortega, denominados "la contra", lo que condujo a la prolongación del conflicto.

En El Salvador, el ejército tomó el poder y sustituía presidentes desde la revolución de 1948. Después de la denominada Guerra de Fútbol contra Honduras en 1969, el militarismo se extendió y generó un malestar social que, al igual que en Nicaragua, afectó a la Iglesia Católica, a los sindicatos y a los sectores populares. Estos últimos se enfrentaron al autoritarismo con diversos movimientos guerrilleros que en la década de los años de ochenta se congregan en el Frente Farabundo Martí de Liberación Nacional (FMLN) y en el Frente Democrático Revolucionario (FDR). La respuesta del ejército y de los grupos paramilitares fue un proceso de dura represión.

Desde 1954, con la invasión de los Estados Unidos, en Guatemala funcionaba una democracia de fachada, pues los militares eran quienes ejercían el poder. Esto provocó que los sectores populares, especialmente indígenas, crearan las Fuerzas Armadas Rebeldes (FAR), de las que se derivó el Ejército Guerrillero de los Pobres (EGP) y la Organización del Pueblo en Armas (ORPA). La respuesta fue una férrea represión. En Honduras, el proceso de democratización iniciado tras la dictadura de Carías (1933 a 1948) era frecuentemente interrumpido por golpes de Estado. No se consolidan los movimientos guerrilleros por una serie de derechos sociales y sindicales que respetó el ejército.

Hacia inicios de los años ochenta, en medio de una crisis económica abrumadora, los militares pierden el control en Centroamérica. Los múltiples procesos de paz iniciados en 1983, condujeron al fin del conflicto tras negociaciones que dieron sus frutos hacia 1990. El resultado fue una crisis económica, un Estado debilitado y un aumento de la pobreza. Tras el desarrollo de una tenue y cuestionable democracia, se han sucedido gobiernos socialistas, capitalistas y moderados en los países, sin que con ello acabe con la criminalidad. Por el contrario, los niveles de violencia en el denominado Triángulo Norte Centro Americano (TNCA), que incluye a Guatemala, El Salvador y Honduras, son superiores a los de algunos países que sufren conflictos armados. El tráfico de drogas, la violencia urbana, la trata de blancas y el trasiego de armas, para mencionar solo algunos, cada vez adquieren más visibilidad e impacto.

Entre los años 2009 y 2011, los niveles de violencia delictiva en la región se recrudecieron por el incremento de operaciones del narcotráfico:

La media anual de tasa homicida en el mundo fue, en el año 2012, de 6,2 homicidios por cada 100000

habitantes. El Salvador presenta un porcentaje de 41,2 por cada 100000 habitantes, mientras que Gua-

temala 39,9 (niveles más elevados actualmente que durante sus respectivas guerras civiles). Honduras,

por su parte, pese a no haber sufrido las consecuencias de una guerra civil en el pasado, es el país con

mayores tasas de violencia en el mundo, con un 90,4, por delante de Sudán (60), Afganistán (6,5) o RDC

(28,3) (Agulló, 2014, p. 1).

El escenario es propicio para el narcotráfico, pues la pobreza generalizada y la expulsión de gente en busca de trabajo en Estados Unidos (migrantes) favorece la alianza con el crimen organizado, amén de la presión de los carteles de la droga sobre la población, adicionado a la violencia perpetrada por grupos armados como las Maras. Además, la guerra contra las drogas en México obligó, a partir de 2006, a modificar las rutas del narcotráfico y los 


\section{DISERTACIONES}

ESTUDIOS

Anuario electrónico de estudios en Comunicación Social

ISSN: $1856-9536$

Doi: dx.doi.org/10.12804/disertaciones.09.02.2016.06

Volumen 9, Número 2 / julio-diciembre 2016

Versión PDF para imprimir desde

equilibrios de poder entre los grupos criminales en la región, lo que causó un aumento de los enfrentamientos por control territorial. A esto se suma la posición geográfica de la zona, ubicada entre Colombia, mayor productor de coca en Sudamérica, y el mayor consumidor que es Estados Unidos.

Los grupos militares que perdieron poder y funcionalidad tras el final de la guerra fría se transformaron en servicios de seguridad privados, lo que justificó su existencia en vista de dos amenazas: el terrorismo y el crimen organizado. Ciertamente, no son nuevas. Muchos de estos grupos se constituyen en ejércitos privados y sustituyen al Estado, que es incapaz de evitar la impunidad y de limitar la corrupción como medio para proporcionar seguridad. Esto conduce irremediablemente a una espiral de violencia y extralegalidad en la resolución de conflictos, que deja como resultado la paramilitarización de la comunidad, la ruptura social y un aumento de los conflictos interpersonales.

A este panorama se unen las políticas de mano dura y la estrategia de militarización de los gobiernos de Guatemala, El Salvador y Honduras, que llevan también a la desestabilización y al aumento de la violencia. En algunas zonas y países del istmo, los paramilitares han construido verdaderas estructuras paralelas al Estado, constituyéndose localmente en autoridades reales y substitutas de la institucionalidad legítima.

En todo este proceso, tanto las Universidades como los medios de comunicación sufren las consecuencias y se ven involucrados en el conflicto. Solo a manera de ejemplo, el 16 de noviembre de 1989 fueron asesinados en El Salvador por los grupos revolucionarios el Rector, el Vicerrector Académico, el Director de Instituto de Derechos Humanos, el director de la Biblioteca de Teología y un profesor de Filosofía, todos ellos docentes, investigadores y escritores de la Universidad Centroamericana José Simeón Cañas de El Salvador, lo mismo que otro jesuita y dos mujeres (Universidad Centroamericana José Simeón Cañas, s.f.). Durante el periodo álgido de los conflictos armados (1981-1990) resultaron muertos 27 periodistas en El Salvador y 34 en Guatemala en el mismo periodo. La mayoría fueron asesinados para acallarlos y hacer callar a otros.

\section{Objetivos y método}

El objetivo de este trabajo es analizar una muestra de los textos académicos referentes a la comunicación en Centro América que se han publicado en forma de libros con respaldo editorial, en revistas reconocidas e indexadas y en informes de organismos internacionales. Es decir, se estudian algunas características de la producción científica sobre comunicación publicada en los formatos referidos, y que es generada por autores adscritos a instituciones académicas centroamericanas. El propósito es hacer un primer acercamiento al análisis coyuntural de los temas de la investigación, realizar comparaciones entre países y considerar la evolución temporal de los textos hallados. No se han considerado las tesis de grado y posgrado, pues requieren de un análisis distinto y en algunos países no hay posgrados, y, en otros, tampoco licenciatura, de modo tal que la muestra no permitiría la realización de estudios comparativos.

Para el ensayo que se presenta ahora, se procedió a revisar las bases de revistas indexadas y los registros del Instituto Tecnológico y de Estudios Superiores de Occidente (ITESO), y también las bases de las bibliotecas de cada 


\section{DISERTACIONES}

ESTUDIOS

Anuario electrónico de estudios en Comunicación Social

ISSN: $1856-9536$

Doi: dx.doi.org/10.12804/disertaciones.09.02.2016.06

Volumen 9, Número 2 / julio-diciembre 2016

Versión PDF para imprimir desde

http://revistas.urosario.edu.co/index.php/disertaciones

país y de bibliotecas generales, como la Congress Library². Se encontraron 242 textos con las características de ser publicados en sellos editoriales y, además, fruto de investigaciones académicas. Los datos obtenidos se clasificaron por quinquenios, según el año de publicación, como se muestra en la figura 1.

Figura 1. Distribución del número de textos académicos por quinquenio

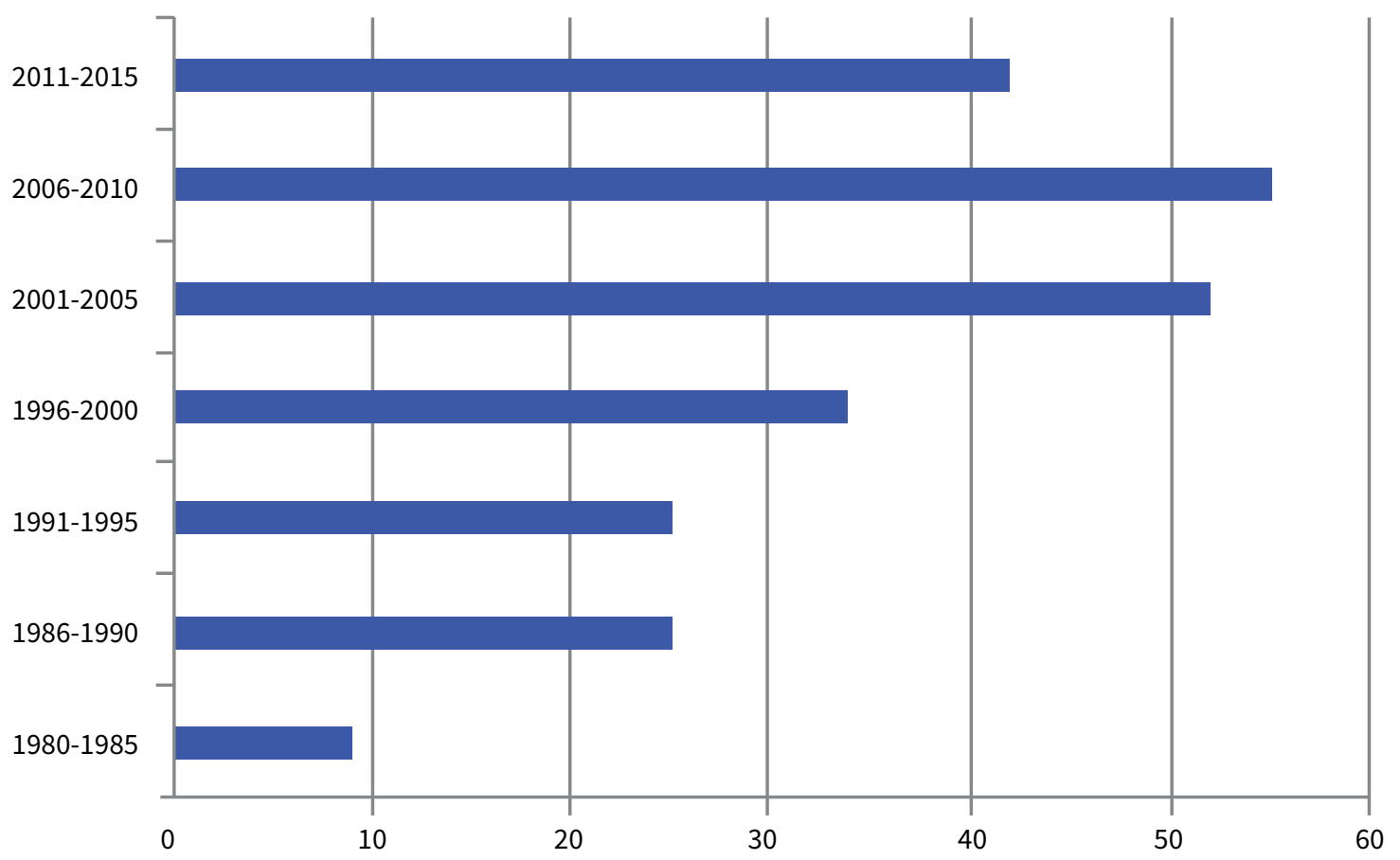

Fuente: elaboración propia.

Los trabajos académicos se registraron en una base de datos que anota el país o países del que se trata, el año de la publicación, el título del texto, el o los temas que estudia, el tipo de documento, el lugar de publicación, la metodología que privilegia, la bibliografía que respalda la investigación y la categoría en la que se ubica; es decir, se agruparon los 242 escritos encontrados en 21 categorías para poder efectuar el análisis. Cuando el texto trataba de uno o más países de la región, se contabilizaba por país, aunque se tratase de un solo escrito.

Las categorías se establecieron considerando el tema o los temas principales de cada texto, de modo tal que se agruparon los escritos según el asunto que trataba con más profundidad. Algunos consideraban diversos tópicos,

2 Los sitios consultados fueron Ebrary, eBook Collection (antes NetLibrary), Harrison Online en Español, oecd iLibrary, sEg digital Library, World e-Book Library, scielo, web.a.ebscohost.com, ieeexplore.ieee.org, revista de sociales ucr, http://onlinelibrary.wiley.com/, jstor en http://www.jstor.org, http://www.worldcat.org/, doaj.org, http://www.cedal.org.co/?s=h\&m=a http://www.revistachasqui.org/, http://www.erevistas.csic.es/ 


\section{DISERTACIONES}

ESTUDIOS

Anuario electrónico de estudios en Comunicación Social

ISSN: $1856-9536$

Doi: dx.doi.org/10.12804/disertaciones.09.02.2016.06

Volumen 9 , Número 2 / julio-diciembre 2016

Versión PDF para imprimir desde

http://revistas.urosario.edu.co/index.php/disertaciones

pero todos referentes a las tecnologías de la información y la comunicación, entonces se ubica en la categoría de tic y comunicación. En el caso de los trabajos que tratan sobre periodismo, hay mayor especificidad que para otras áreas, y entonces se refieren a la práctica periodística, a la legislación o a la prensa en los periodos de crisis y algunos solo al periodismo como práctica. En tal caso, se establecieron categorías para cada uno de ellos. Los asuntos que no se ubican claramente en ninguna de las categorías que se derivan de los temas de los textos se ubican en la casilla de 'otros'.

Está claro que en esta investigación no se incluye la totalidad de los trabajos publicados. Solo se tomó una muestra representativa de los estudios registrados en las principales bases de datos que se mencionaron. Resta por hacer una búsqueda por autor o en otros repositorios de manera tal que se puedan rastrear por otras vías las investigaciones existentes. Esto es un trabajo adicional que no se efectúa para esta entrega. Con los datos que se extrajeron, se realizaron cruces de variables y se determinaron algunos hallazgos que permiten establecer generalidades sobre el desarrollo de la reflexión académica en torno a la comunicación en el área centroamericana.

Finalmente, es preciso aclarar que este texto es una aproximación a un tema que debe ser abordado con minuciosidad, en este se deben identificar todos los productos de investigaciones académicas que se publican en Centroamérica y analizar las corrientes teóricas y metodológicas que se privilegian, también es necesario hacer un balance de los hallazgos y de su impacto en la región, por lo menos en el campo de la comunicación.

\section{Resultados}

\subsection{Evolución de los trabajos académicos sobre comunicación en Centroamérica}

Los estudios referentes a la comunicación que están presentes a partir del segundo quinquenio de la década del ochenta son numerosos y la mayoría contemplan varios países en su análisis, de modo que buena parte de los 242 textos considerados examinan particularidades del tema estudiado en varias naciones. Como recoge la tabla 1 , los resultados de las investigaciones se publican principalmente en formato de libro donde intervienen uno o más autores y con respaldo editorial. Los artículos de revistas son menos frecuentes, pero se divulgan en publicaciones de prestigio académico, fundamentalmente editadas por universidades. La mayoría se ubican en la Revista Chasqui, Anuario de Estudios Sociales Centroamericanos, Revista de Ciencias Sociales, Razón y Palabra, Revista Latina de Comunicación, entre otras. Buena parte de ellas se editan en América Latina y están respaldadas por universidades, editoriales u organizaciones de prestigio internacional. 


\section{DISERTACIONES}

ESTUDIOS

Anuario electrónico de estudios en Comunicación Social

ISSN: $1856-9536$

Doi: dx.doi.org/10.12804/disertaciones.09.02.2016.06

Volumen 9, Número 2 / julio-diciembre 2016

Versión PDF para imprimir desde

http://revistas.urosario.edu.co/index.php/disertaciones

Tabla 1. Distribución de las referencias a los países incluidos en el estudio en los textos académicos analizados (1980-2015)

\begin{tabular}{|l|c|c|c|c|}
\hline \multicolumn{1}{|c|}{ País } & Libros & Revistas & Informes & Total \\
\hline Belice & 8 & 1 & 1 & 10 \\
\hline $\begin{array}{l}\text { Costa Rica y } \\
\text { El Salvador }\end{array}$ & 84 & 68 & 1 & 153 \\
\hline El Salvador & 60 & 39 & 2 & 101 \\
\hline Guatemala & 69 & 41 & & 110 \\
\hline Honduras & 54 & 26 & & 80 \\
\hline Nicaragua & 62 & 30 & & 92 \\
\hline Panamá & 62 & 25 & 1 & 88 \\
\hline Total & 399 & 230 & 5 & 634 \\
\hline
\end{tabular}

Fuente: elaboración propia.

Los estudios publicados proliferan a partir del año 1990, como se evidencia en la figura 1, pero aumentan significativamente con el inicio del siglo xxı y continúa la tendencia en los años siguientes. El país sobre el que más artículos y libros se publican es Costa Rica, la mayoría con respaldo de la Universidad de Costa Rica (UCR), la Universidad Estatal a Distancia (UNED) y, en pocos casos, la Universidad Nacional (UNA). Las tres son Centros de Educación Superior públicos. En la ucr funcionó una comisión de investigación en comunicación desde 1992 que se convirtió en Centro de Investigación en Comunicación (сісом) en abril de 2012. Esto favoreció los estudios sobre la materia. Además, existen al menos cinco revistas indexadas que publican avances o investigaciones referentes a comunicación.

En algunos países el número de publicaciones demostró un verdadero crecimiento después del año 2000. Guatemala pasó de 13 publicaciones en el quinquenio de 1996 al 2000 a 25 después de 2001; en El Salvador aumentó de 15 a 26 de 1990 a 2001; en Nicaragua hay 24 trabajos de 2006 a 2010, pero disminuye a 17 después de 2001; en Honduras aumentan muy poco después de 1991, y algo similar ocurre en Panamá.

Este incremento se explica por varios factores. Por una parte, la tecnología facilita la escritura de textos por medio de diversos programas diseñados para el procesamiento de textos, imágenes, números, etc. Internet permite el acceso a bibliotecas digitales y a bases de publicaciones académicas de texto completo, a archivos y a informaciones gubernamentales, entre otros; con estas herramientas, las y los investigadores pueden realizar más y mejores estudios sobre los tópicos más diversos. Por otra parte, las posibilidades de desplazamiento de personas para estudiar en diversos países del mundo facilitan el encuentro de numerosas escuelas de pensamiento sobre un área y enriquece el análisis y la comprensión de los fenómenos. Unido a esto último, una serie de 


\section{DISERTACIONES}

Estudios

Anuario electrónico de estudios en Comunicación Social

ISSN: $1856-9536$

Doi: dx.doi.org/10.12804/disertaciones.09.02.2016.06

Volumen 9, Número 2 / julio-diciembre 2016

Versión PDF para imprimir desde

http://revistas.urosario.edu.co/index.php/disertaciones

académicos inician investigaciones en los centros de enseñanza superior y el conocimiento sobre la comunicación se desarrolla exponencialmente.

A esto se suma el hecho de que en Guatemala y El Salvador las universidades promueven las investigaciones en torno a la comunicación. La Universidad de San Carlos de Guatemala (USAC), Casa de Enseñanza Superior pública, abrió la carrera de Ciencias de la Comunicación en la década de 1960 con salidas de bachillerato, licenciatura, maestría y doctorado. Las investigaciones que se realizan para obtener los grados son una fuente importante de aportes a los estudios de comunicación, cuyos resultados son publicados en forma de artículos y libros académicos.

La Universidad de El Salvador abrió un Departamento de Periodismo desde el 5 de mayo de 1965, graduando licenciados en la materia. Casi tres décadas después, en 1992, la Universidad Centroamericana José Simeón Cañas (UCA) imparte la licenciatura y la maestría en Comunicación Social (Departamentos, s.f.), lo mismo que la Universidad Dr. José Matías Delgado (UJMD). La primera es propiedad de la orden de los Jesuitas y ha promovido la investigación y la divulgación de los estudios realizados en el campo de la comunicación, siendo una universidad privada.

En Honduras, la situación es un poco distinta. La Universidad Nacional Autónoma de Honduras (UnAH) imparte la carrera de Periodismo y, junto con la Universidad Complutense de Madrid, una especialidad en Comunicación y Desarrollo. Los estudios derivados de ambas instancias son reducidos. La iniciativa la toman investigadores procedentes de otros países. De hecho, de los 80 textos que se refieren a Honduras, solo 7 (10\%) tratan exclusivamente la comunicación en ese país.

Una situación similar ocurre en Nicaragua, donde solo el 16,3\% de los documentos se refieren únicamente a ese país. Allí funciona la Universidad Centroamericana, entidad privada que imparte la licenciatura en comunicación y además tiene el Centro de Investigación de la Comunicación (cinco) que

[...] es una institución de la sociedad civil nicaragüense especializada en estudios de comunicación, cul-

tura, democracia y opinión pública, con especial énfasis en el estudio de los medios de comunicación, su

rol social y político en la construcción de la democracia. Fue creado en 1990 y desde 1995 funciona como

una asociación sin fines de lucro (cInco, s.f.).

Ha generado una serie de publicaciones de análisis de la libertad de expresión, género y comunicación, entre otras.

Los textos publicados sobre Panamá no son escasos. El hecho de contar con una facultad de comunicación en la Universidad de Panamá (institución oficial autónoma, desde 1984) con cuatro carreras -Comunicación Corporativa, Periodismo, Publicidad, y Producción Audiovisual, aunque la carrera de Periodismo existe desde la década de 1960- ha favorecido los análisis académicos de la comunicación. Pero, sobre todo, las condiciones geográficas de Panamá, su ubicación estratégica y la presencia del canal, más la implementación de una propuesta neoliberal, ha contribuido a que se desarrollen estudios referentes al papel de la comunicación en ese proceso. 


\section{DISERTACIONES}

ESTUDIOS

Anuario electrónico de estudios en Comunicación Social

ISSN: 1856-9536

Doi: dx.doi.org/10.12804/disertaciones.09.02.2016.06

Volumen 9, Número 2 / julio-diciembre 2016

Versión PDF para imprimir desde

http://revistas.urosario.edu.co/index.php/disertaciones

\subsection{Temas de la investigación centroamericana sobre comunicación}

Los temas que tratan los textos académicos son múltiples. Los documentos se agruparon en 21 categorías, según la temática principal del escrito. Al ordenarlas por quinquenio, se evidencia una coincidencia con los cambios tecnológicos y con los contextos, especialmente económicos y políticos, específicos de cada país de la región (tabla 2).

Tabla 2. Distribución de los textos académicos por año y categoría temática

\begin{tabular}{|c|c|c|c|c|c|c|c|c|}
\hline \multirow[b]{2}{*}{ Categorías } & \multicolumn{7}{|c|}{ Años } & \multirow[b]{2}{*}{ TOTAL } \\
\hline & $\begin{array}{l}1980- \\
1985\end{array}$ & $\begin{array}{l}1986- \\
1990\end{array}$ & $\begin{array}{l}1991- \\
1995\end{array}$ & $\begin{array}{l}1996- \\
2000\end{array}$ & $\begin{array}{l}2001- \\
2005\end{array}$ & $\begin{array}{l}2006- \\
2010\end{array}$ & $\begin{array}{l}2011- \\
2015\end{array}$ & \\
\hline Comunicación y ciudadanía & 1 & & 1 & 2 & 2 & 3 & & 9 \\
\hline Comunicación y educación & & 1 & 3 & 1 & & & 1 & 6 \\
\hline Efectos de los medios & & 2 & & & 2 & 1 & & 5 \\
\hline Enseñanza de la comunicación & 1 & & & & & 1 & 1 & 3 \\
\hline Géneros periodísticos & 1 & & 2 & & 4 & 1 & & 8 \\
\hline Historia & 3 & 6 & 5 & 5 & 9 & 8 & 4 & 40 \\
\hline Lista de medios & & 1 & 2 & & & & & 3 \\
\hline $\begin{array}{l}\text { Medios de comunicación y } \\
\text { género }\end{array}$ & & & & 1 & & 1 & 1 & 3 \\
\hline $\begin{array}{l}\text { Medios de comunicación y poder } \\
\text { político }\end{array}$ & & 1 & 1 & 8 & 7 & 4 & 4 & 25 \\
\hline Periodismo práctico & & & & 2 & 2 & 4 & 3 & 11 \\
\hline Periodismo rural & & & & 1 & & & 1 & 2 \\
\hline Periodismo y legislación & & & & 1 & & 1 & 3 & 5 \\
\hline Periodismo y paz & & & & 1 & 1 & & & 2 \\
\hline Periodismo en periodos de crisis & & 8 & 5 & 3 & 2 & 2 & 3 & 23 \\
\hline Producción audiovisual & & 3 & 1 & & & 1 & 3 & 8 \\
\hline Publicidad & & & 2 & 1 & & 3 & 2 & 8 \\
\hline Relaciones públicas & & 1 & & & & 2 & 2 & 5 \\
\hline Telecomunicaciones & 1 & & 2 & 8 & 12 & 7 & & 31 \\
\hline Televisión & 2 & 1 & 1 & & & & & 4 \\
\hline Teoría de la comunicación & & 1 & & & & & & 1 \\
\hline TIC y comunicación & & & & & 11 & 16 & 14 & 41 \\
\hline TOTAL & 9 & 25 & 25 & 34 & 52 & 55 & 42 & 242 \\
\hline
\end{tabular}

Fuente: elaboración propia

Es evidente que en los años ochenta prevalece un interés por el recuento histórico del periodismo y una preocupación por denunciar la tergiversación de los medios, su papel en las estrategias ideológicas de los bandos en 


\section{DISERTACIONES}

ESTUDIOS

Anuario electrónico de estudios en Comunicación Social

ISSN: $1856-9536$

Doi: dx.doi.org/10.12804/disertaciones.09.02.2016.06

Volumen 9, Número 2 / julio-diciembre 2016

Versión PDF para imprimir desde

http://revistas.urosario.edu.co/index.php/disertaciones

disputa y el rol de los periodistas en esa situación. Son, en su mayoría, estudios apoyados en la teoría de la dependencia y en la polarización ideológica en el marco de la Guerra Fría. Ante el conflicto bélico, no es de extrañar la cuantía de estudios (13) referentes al periodismo en periodo de crisis en los años comprendidos entre 1986 y 1995.

Las teorías desarrollistas, expuestas en la Comisión Económica para América Latina y el Caribe (CEPAL) en 1949 son asideros teóricos de los trabajos de investigación que se divulgan sobre comunicación en Centroamérica durante 1980 y 1995 (Castañeda \& Morales, 2011). El periodismo científico, por ejemplo, se consideraba un motor para alcanzar el desarrollo. Hay una evidente preocupación por los efectos de los medios y la manipulación de las "conciencias" colectivas y su rol como promotores de paz y democracia en la convulsa Centroamérica. Las investigaciones giran en torno al papel de las agencias noticiosas que responden a intereses de sus países de origen y proponen la urgencia de contar con intercambios informativos neutrales.

La vinculación entre la comunicación y la educación es un tema recurrente entre 1986 y el 2000, y lo es también la insistencia en el fomento de la comunicación popular, dar voz a quienes no la tienen como una alternativa para superar las crisis. Es una etapa en la que germina una crítica epistemológica que conduce a la reflexión sobre la estructura de poder de los medios, la desinformación y el control del flujo de la información y la necesidad de democratizarlo, las industrias culturales y la socialización de las "conciencias", la subordinación a los polos de poder, la comunicación alternativa o popular y la preocupación por un nuevo orden mundial de la información.

Después de 1996, las telecomunicaciones ocupan un lugar central. El advenimiento y posesión del neoliberalismo, evidente ya en la década de 1990, conduce a enterrar las viejas teorías y a proponer las tecnologías como las determinantes del cambio, como dice Martín Barbero (1980), se amarra a una concepción instrumentalista de la técnica, el peso histórico y el entramado político.

El fin de la Guerra Fría y los procesos de paz centroamericanos que ocupan buena parte de la década de 1990 condujeron al surgimiento de nuevos temas en las investigaciones de la comunicación: medios de comunicación y género, prensa y poder político, la práctica profesional y los vínculos entre la comunicación y la ciudadanía. En organismos internacionales se ha despertado una preocupación permanente por la libertad de expresión y el asesinato masivo de periodistas en Centroamérica (Vega, 2012).

Con el cambio de siglo, las tendencias neoliberales, lejos de desaparecer, se afianzan y con ellas la preocupación de los académicos por temas relacionados con las telecomunicaciones, sus alcances técnicos y su condicionamiento económico y el uso y desarrollo de las tecnologías de la información y la comunicación (Tic). Los textos de la muestra evidencian un apego a la nueva tendencia de pensamiento que privilegia la eficiencia y el pragmatismo. Consecuentes con el modelo de desarrollo modernizador que le concede al mercado, su papel de eje que dirige y modele los procesos sociales y educativos de América Latina en general y Centroamérica en particular, las investigaciones refieren a la regulación y competencia de las telecomunicaciones, el periodismo digital, el acceso a las tecnologías de la información y la comunicación y la brecha digital, las políticas de las telecomunicaciones y las oportunidades de negocio que brindan, los procesos de privatización y el papel del Estado, el desarrollo de las competencias, la evolución de la cultura digital, la educación y la comunicación en la era digital y el impacto económico de la red de Internet. También se analizan las nuevas formas de sociabilidad a la que conduce la web, el ciberperiodismo y, sobre todo, el comercio móvil que se facilita con las TIC y los retos que plantea la globalización para la innovación y el crecimiento económico. 


\section{DISERTACIONES}

ESTUDIOS

Anuario electrónico de estudios en Comunicación Social

ISSN: 1856-9536

Doi: dx.doi.org/10.12804/disertaciones.09.02.2016.06

Volumen 9, Número 2 / julio-diciembre 2016

Versión PDF para imprimir desde

http://revistas.urosario.edu.co/index.php/disertaciones

En 1998 Esteinou (1998) advertía una situación similar en México y en América Latina, en general. En su opinión, tras la prevalencia del neoliberalismo "los proyectos de investigación de apoyo al desarrollo social han quedado crecientemente marginados o han desaparecido en la medida en que no han respondido a los intereses lucrativos del mercado" (p. 5).

Todo esto conduce a repensar las mallas curriculares de las escuelas de comunicación, que se adaptan a las nuevas tendencias y a las implicaciones que tienen sobre la práctica periodística, por una parte, y de las áreas de relaciones públicas, producción audiovisual y multimedial, y la publicidad. La presencia de diversas disciplinas en los estudios de la comunicación conduce a una amplitud en la gama temática de las investigaciones en Centroamérica. La educación, la psicología (en los textos sobre efectos de los medios), la sociología y las ciencias políticas son algunas de las disciplinas que enriquecen la investigación y que evidencian la importancia de la transdisciplinariedad en los estudios de la comunicación.

En la muestra, no hay una preocupación fundamental por las teorías como asidero para la explicación de los fenómenos. A pesar de las temáticas tratadas, ni el enfoque positivista, en sus diversas manifestaciones - análisis funcional, influencia personal, usos y gratificaciones, establecimiento de la agenda, análisis de cultivo, sociología de la producción de mensajes-, ni el enfoque teórico crítico - análisis de los procesos comunicacionales, las características de las condiciones económicas, sociales, de educación, de poder y hegemonía en los diferentes sistemas contemporáneos para cuestionar los roles que cumple la comunicación en la preservación del sistema social y el papel de los mensajes en la difusión de la ideología dominante- (León, 2002) permean de manera decidida la mayoría de los textos.

\section{Una región heterogénea}

\subsection{Belice}

La heterogeneidad de la región se evidencia también en los textos académicos. En Belice, por ejemplo, ninguno de los documentos se refiere en exclusiva al país. Todos los estudios tratan a toda la región e incluyen a Belice en sus análisis. El tema que con más frecuencia se trata son las Tecnologías de la Comunicación y la Información, que se privilegia en el quinquenio de 2011 a 2015, cuando el impacto tecnológico es evidente en todas las sociedades del mundo (figura 2). 


\section{DISERTACIONES}

ESTUDIOS

Anuario electrónico de estudios en Comunicación Social

ISSN: 1856-9536

Doi: dx.doi.org/10.12804/disertaciones.09.02.2016.06

Volumen 9, Número 2 / julio-diciembre 2016

Versión PDF para imprimir desde

http://revistas.urosario.edu.co/index.php/disertaciones

Figura 2. Distribución de los textos académicos referentes a Belice por periodos

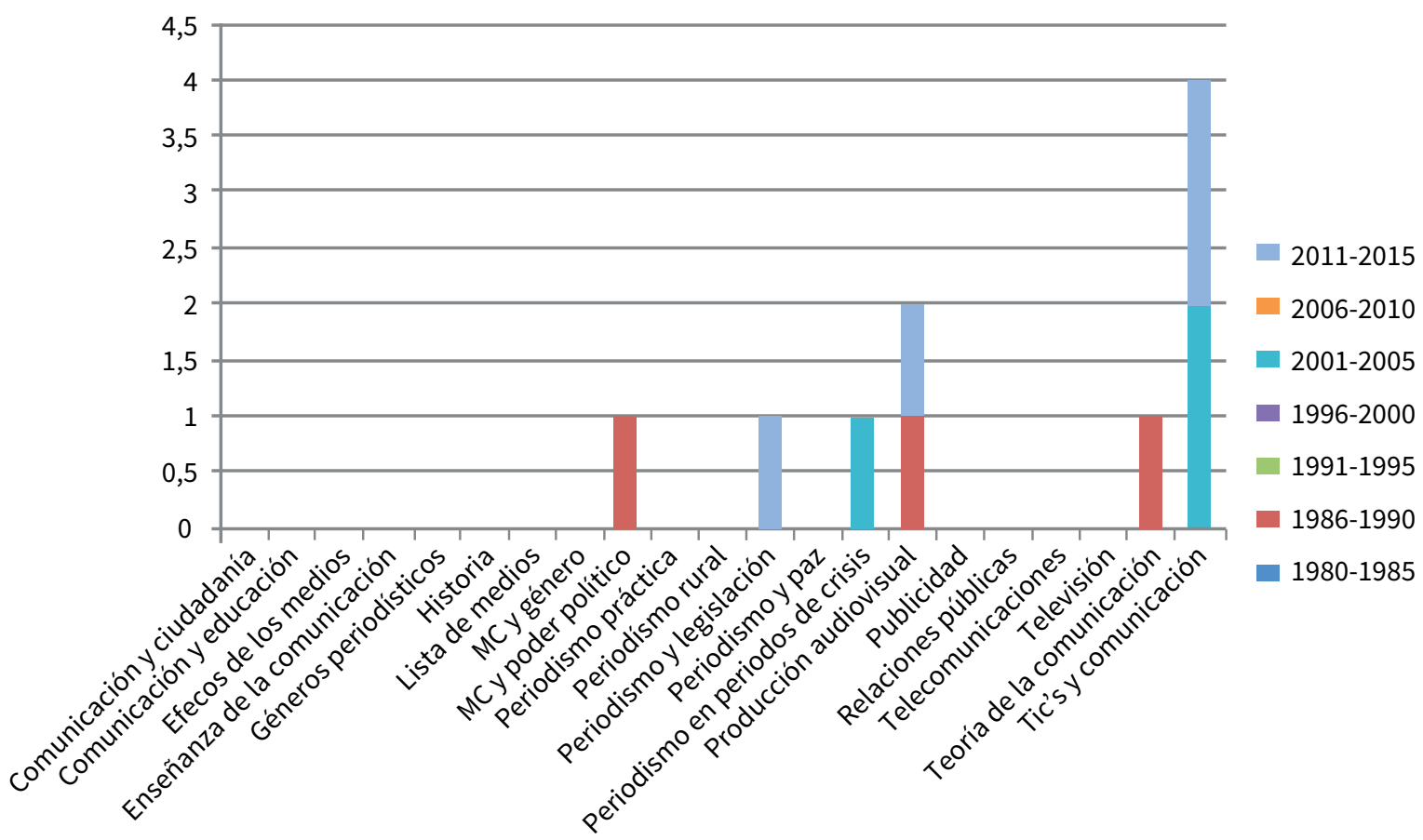

Fuente: elaboración propia

Belice se independizó del Reino Unido el 21 de septiembre de 1981 tras intensas disputas y negociaciones con Guatemala, que reclamaba el territorio. Su gobierno, una monarquía constitucional parlamentaria, se diferencia del resto de la región. El jefe de Estado de iure es la Reina Isabel II, quien es la monarca del Reino Unido, y cuya representación en el país la tiene el Gobernador General. Durante la guerra que afectó fundamentalmente a Guatemala, El Salvador y Nicaragua, Belice permaneció al margen. Tenía su propia dinámica en un proceso de independencia muy largo, de hecho no fue sino hasta 1994 cuando se retiraron los soldados británicos. Con una población que no llega a los 340 mil habitantes en un territorio de $22966 \mathrm{~km}^{2}$, tiene siete periódicos principales, dos canales de televisión, cinco emisoras de radio y varias revistas. Su idioma oficial es el inglés, aunque también se habla español, kriol y lenguas mayenses. En Belice no hay ni facultad ni carrera de periodismo o de comunicación. Esto podría, en parte, explicar la ausencia de investigaciones académicas en ese país.

\subsection{Costa Rica}

En Costa Rica, que no sufrió en su territorio el conflicto centroamericano de las décadas de 1970 y 1980, la cantidad de textos supera al resto de los países de la región, como se observa en la tabla 1. Los temas que tratan los textos académicos con más frecuencia son las tecnologías de la comunicación y la información (TIC), las telecomu- 


\section{DISERTACIONES}

ESTUDIOS

Anuario electrónico de estudios en Comunicación Social

ISSN: 1856-9536

Doi: dx.doi.org/10.12804/disertaciones.09.02.2016.06

Volumen 9, Número 2 / julio-diciembre 2016

Versión PDF para imprimir desde

http://revistas.urosario.edu.co/index.php/disertaciones

nicaciones y la historia de la comunicación social (figura 3). Las tIc son un fenómeno mundial que revolucionó las comunicaciones y las formas de sociabilidad. Este impacto provocó que desde el inicio del siglo xxı hubiese una preocupación académica en aumento por analizar la convergencia mediática a la que condujeron las tecnologías, su influencia en los cambios en la enseñanza de la comunicación en general, su impacto sobre la forma de hacer periodismo, los cambios en la publicidad, en los públicos, en las comunicaciones internas y externas de las organizaciones y, en particular, sobre la producción audiovisual que ahora también es multimedial.

Figura 3. Distribución de los textos académicos referentes a Costa Rica por periodos

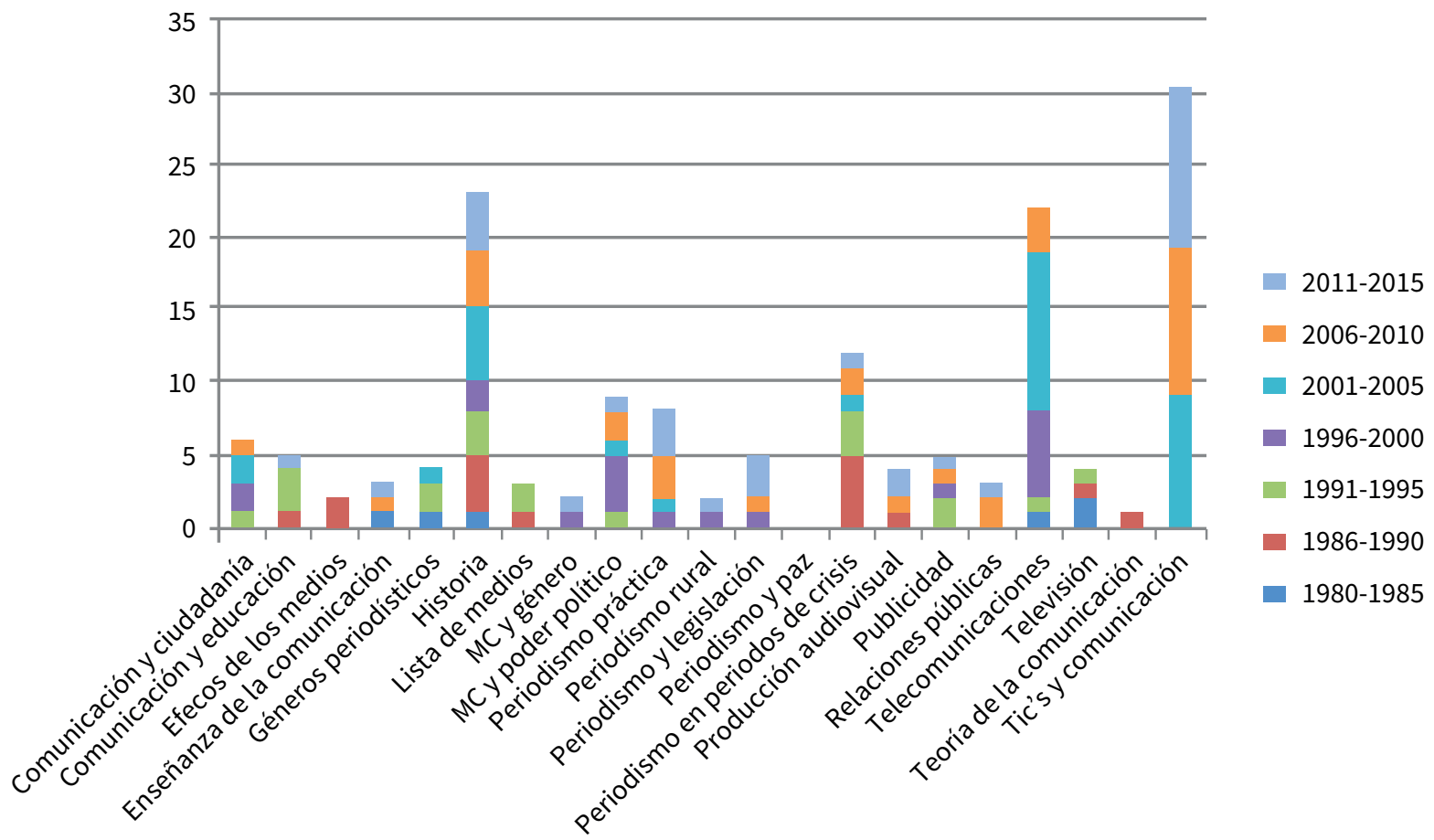

Fuente: elaboración propia

Las telecomunicaciones aparecen en los análisis académicos desde el quinquenio de 1980, pero se acrecientan significativamente de 2001 a 2005. En ese momento, desaparece el monopolio de las telecomunicaciones y se inicia un proceso de apertura que ha conducido a múltiples análisis. En la década de 1980 se empieza el proceso de iniciación del sector de telecomunicaciones con el ingreso de Millicom a Costa Rica para brindar telefonía celular. Sus operaciones se declaran inconstitucionales, pues el monopolio lo tenía el Instituto Costarricense de Electricidad (ICE). No obstante, en marzo de 2000 un proyecto de ley es presentado y aprobado en primer debate en la Asamblea Legislativa que pretendía abrir la competencia de los servicios ofrecidos por el IcE. Esto condujo a una serie de manifestaciones públicas, que obligaron al gobierno de turno a archivar el proyecto. 


\section{DISERTACIONES}

ESTUDIOS

Anuario electrónico de estudios en Comunicación Social

ISSN: 1856-9536

Doi: dx.doi.org/10.12804/disertaciones.09.02.2016.06

Volumen 9, Número 2 / julio-diciembre 2016

Versión PDF para imprimir desde

http://revistas.urosario.edu.co/index.php/disertaciones

No será sino luego del 3 de octubre del 2002 cuando se inicie el proceso de negociación del tratado de Libre Comercio entre Estados Unidos y Centroamérica, por iniciativa del primero. La delegación estadounidense solicita la apertura de las telecomunicaciones en el acuerdo comercial y así es firmado por cuatro países centroamericanos: El Salvador, Guatemala, Honduras y Nicaragua, en 2003; y Costa Rica lo hará cuatro años después (Trejos, 2013). Esto implicó cambios no solo económicos, sino también políticos, y se convierte en preocupación de los académicos por sus impactos en la enseñanza de la comunicación y en la aplicabilidad de las tecnologías.

La historia de la comunicación ha sido una preocupación frecuente que busca conocer el desarrollo de las diferentes especialidades: periodismo, publicidad y, en menor medida, las Relaciones Públicas y la Producción Audiovisual (radio, cine, Televisión y multimedia). En la década de 1980 hay una inquietud fundamental por la crisis centroamericana y el papel del periodismo y de los periodistas. El conflicto evidenció, en el contexto de la Guerra Fría, la importancia de la prensa para aminorar o acrecentar una contienda que estaba desangrando la región. Los medios de comunicación respondieron a los intereses de uno u otro bando sin consideraciones éticas o consecuencias sociales. Los textos académicos analizan no solo el contexto de la guerra y la prensa sino también las diversas posturas ideológicas que median en torno a la situación que para 1990 aun no tenía visos de solución, a pesar del derrumbamiento del grupo soviético.

\subsection{El Salvador}

La relación de la prensa y la Guerra Fría, es uno de los temas más destacados sobre los que tratan los estudios de comunicación en El Salvador (figura 4), lo mismo que el de las telecomunicaciones y de las tic. Los trabajos referentes a las telecomunicaciones coinciden con el momento de la discusión y final aprobación del Tratado de Libre Comercio que ya se ha referido, y lo de las TIC, con su propio avance. El periodismo en periodos de crisis se explica, en mucho, por el conflicto sin precedentes que sufrió El Salvador en las décadas de 1980 y buena parte de 1990. En ese país la muerte de periodistas fue copiosa y la censura absoluta, mientras los asesinatos de parte de los bandos en disputa se contaban por miles. Los trabajos académicos en torno a este conflicto no se limitan únicamente a $\mathrm{El}$ Salvador en exclusiva sino que lo comparan con lo que acontece en Guatemala y en Nicaragua. 


\section{DISERTACIONES}

Figura 4. Distribución de los textos académicos referentes a El Salvador por periodos

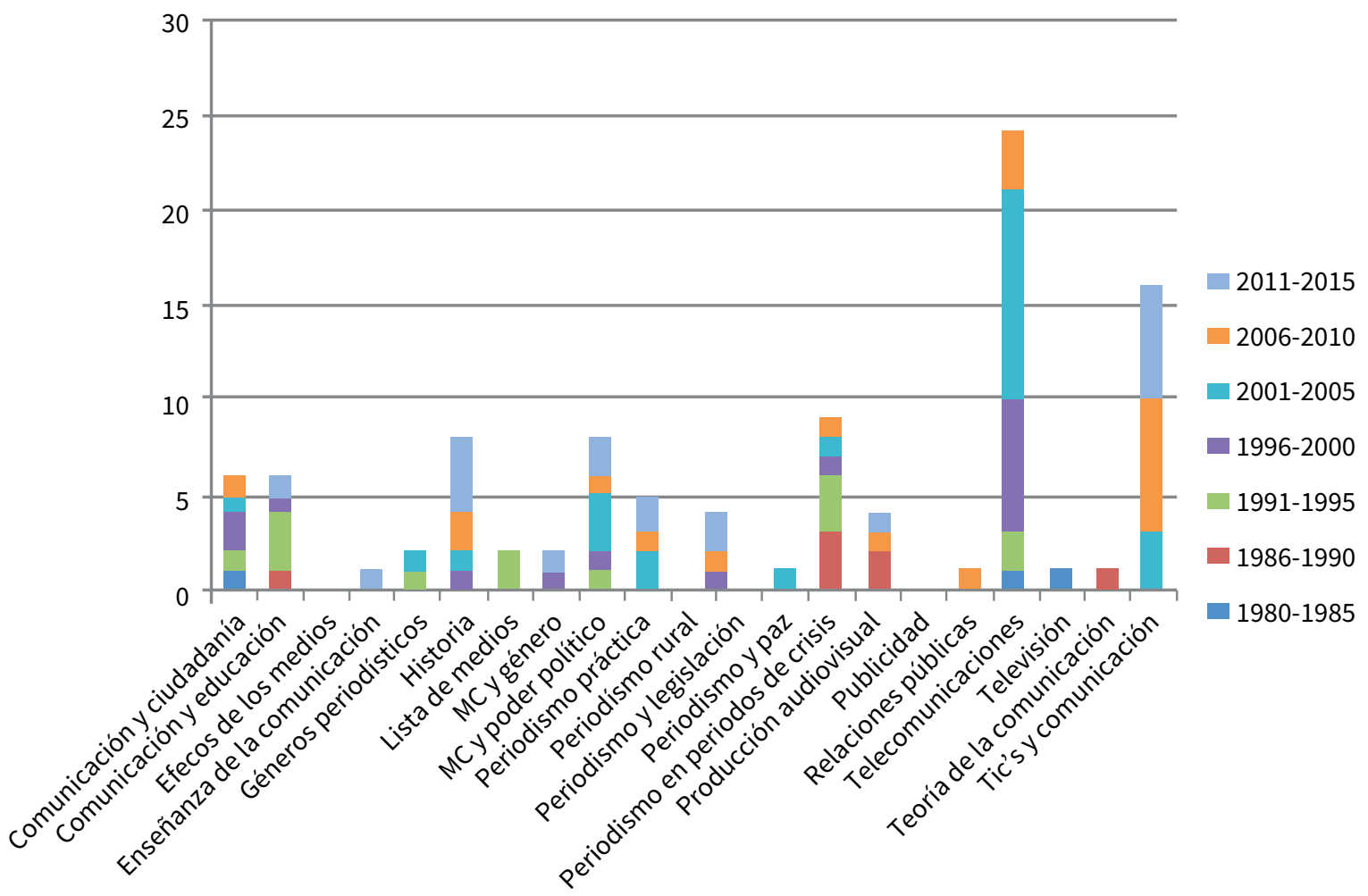

Fuente: elaboración propia

\subsection{Guatemala}

Como se aprecia en la figura 5, los textos que analizan el periodismo durante de crisis en Guatemala son los terceros en importancia después de las telecomunicaciones y las TIc. Los medios de comunicación y el poder político también son temas recurrentes, en particular, en la década de 1990 y se retoma en el último quinquenio cuando la crisis, producto de la violencia generada por el narcotráfico y el crimen organizado, ha permeado los medios de comunicación. 


\section{DISERTACIONES}

\section{ESTUDIOS}

Anuario electrónico de estudios en Comunicación Social

ISSN: 1856-9536

Doi: dx.doi.org/10.12804/disertaciones.09.02.2016.06

Volumen 9, Número 2 / julio-diciembre 2016

Versión PDF para imprimir desde

Figura 5. Distribución de los textos académicos referentes a Guatemala por periodos

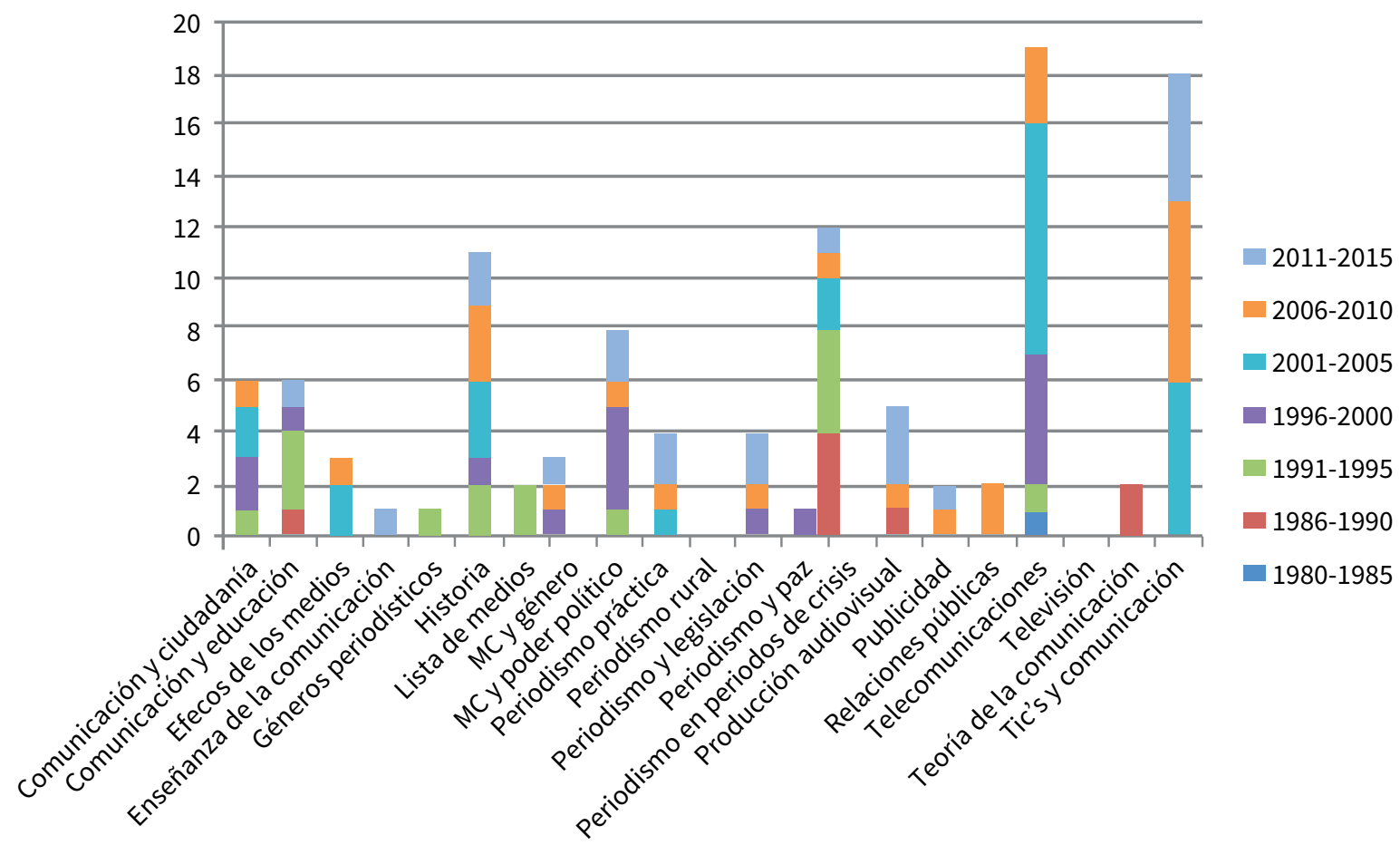

Fuente: elaboración propia

\subsection{Honduras}

Los textos sobre las comunicaciones en Honduras se preocupan por las telecomunicaciones, como en el resto de la región, y las Tecnologías de la Información y la Comunicación, como lo expone la figura 6. Llaman la atención los trabajos referentes a periodismo y legislación, un interés de los académicos por analizar la regulación del ejercicio de la profesión y el papel de los medios. Sobre todo, la práctica periodística es un tema que preocupa a quienes estudian la comunicación en ese país, quizá porque la enseñanza del periodismo en el ámbito universitario se consolidó en el año 2008 y los estudios justifican la necesidad de la carrera. 


\section{DISERTACIONES}

ESTUDIOS

Anuario electrónico de estudios en Comunicación Social

ISSN: 1856-9536

Doi: dx.doi.org/10.12804/disertaciones.09.02.2016.06

Volumen 9, Número 2 / julio-diciembre 2016

Versión PDF para imprimir desde

Figura 6. Distribución de los textos académicos referentes a Honduras por periodos

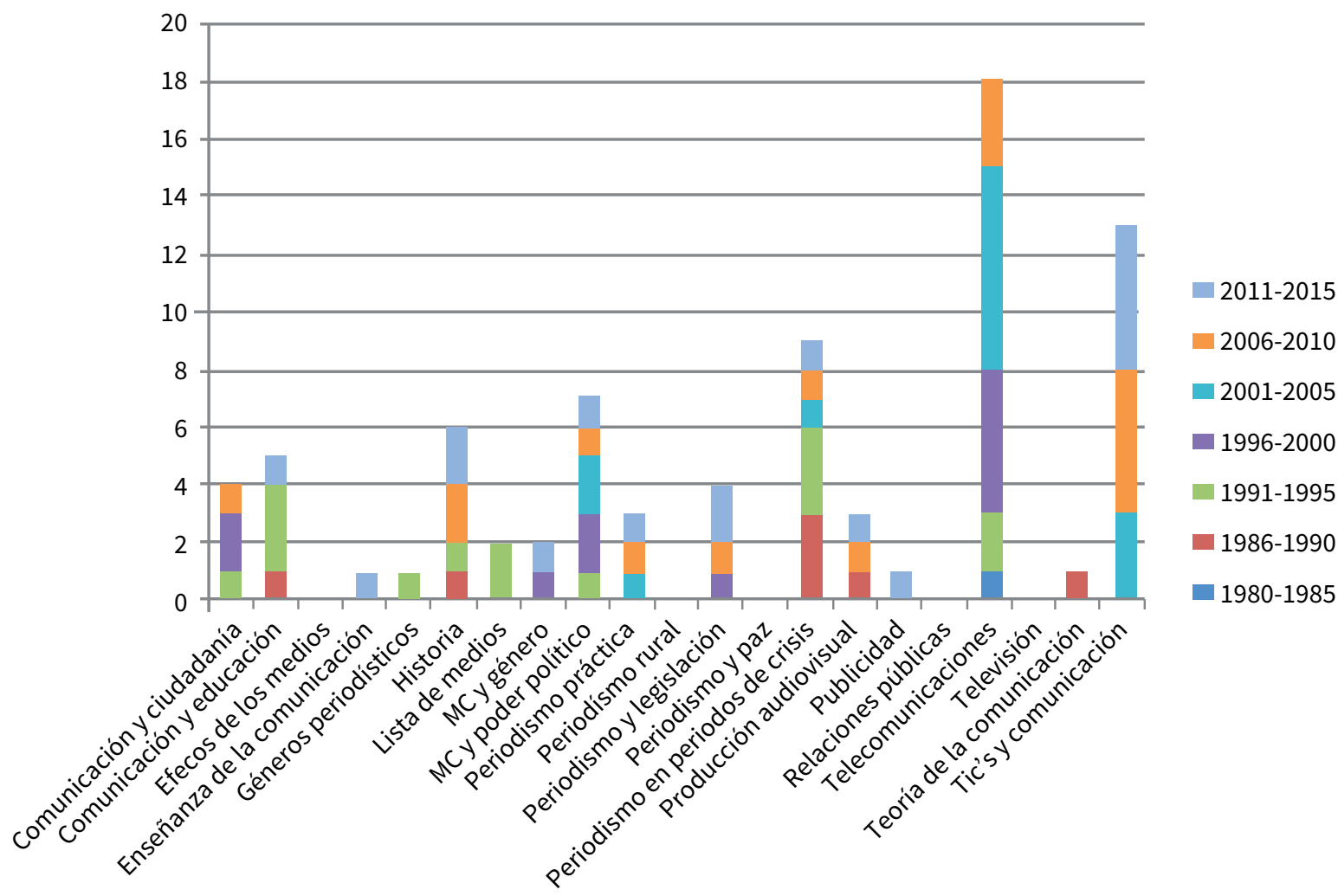

Fuente: elaboración propia.

Como se ha referido, en Honduras el crimen organizado es uno de los principales problemas que enfrenta el país. Esto ha conducido irremediablemente a una autocensura de parte de los comunicadores que posiblemente también afecta a los y las investigadoras, lo que explicaría la presencia mayoritaria de textos académicos editados en otros países por estudiosos o por organismos internacionales tratando la comunicación en Honduras desde diversas perspectivas temáticas.

Efectivamente, de todo lo publicado sobre comunicación en Honduras, solo 7 textos de la muestra hacen referencia de manera exclusiva a ese país. En 2002, hay una preocupación por la participación de los medios en la construcción democrática, y en 2013 es el tema del periodismo en periodos de crisis. Una explicación de este fenómeno podría ser que el 28 de junio de 2009 el presidente José Manuel Zelaya fue destituido tras un golpe de Estado y sustituido por el liberal Roberto Micheletti. El hecho fue condenado por la comunidad y los organismos internacionales. Esto provocó un resquebrajamiento y una polarización política, social y económica en el país que aún en 2015 no ha logrado superar, en particular por la férrea represión desatada como alternativa. Los medios de comunicación y 


\section{DISERTACIONES}

ESTUDIOS

Anuario electrónico de estudios en Comunicación Social

ISSN: 1856-9536

Doi: dx.doi.org/10.12804/disertaciones.09.02.2016.06

Volumen 9, Número 2 / julio-diciembre 2016

Versión PDF para imprimir desde

http://revistas.urosario.edu.co/index.php/disertaciones

los periodistas han sido uno de los sectores más afectados. El número de comunicadores asesinados alcanza cifras alarmantes: 30 de 2009 a 2015 y el cierre de medios y las agresiones van en aumento (Human Rights Watch, p. 3).

\subsection{Nicaragua}

En la muestra analizada de publicaciones referentes exclusivamente a Nicaragua (16,30\% de las investigaciones), hay una inquietud por el papel de los medios en la construcción de la democracia, su vinculación con el poder político y su papel en periodos de crisis, en particular en la década de 1980 cuando el conflicto aún persiste. De hecho, en el quinquenio 1985-1990, Daniel Ortega, líder del Frente Sandinista de Liberación Nacional, que derrocó a la familia Somoza, se mantiene en el poder aduciendo su adhesión a la ideología socialista. En las elecciones de 1990, y hasta 2007, gobiernan en Nicaragua grupos opositores al sandinismo de Ortega, y con ellos se inicia el proceso de privatización de las telecomunicaciones y la implementación de las políticas neoliberales. En las elecciones de 2007 llega al poder nuevamente Daniel Ortega y, tras maniobras políticas cuestionadas, se mantendrá hasta 2017. Esto conduce a una serie de investigaciones tendentes a analizar el papel del poder político y su relación con los medios de comunicación y la responsabilidad de estos en el devenir sociopolítico.

Figura 7. Distribución de los textos académicos referentes a Nicaragua por periodos

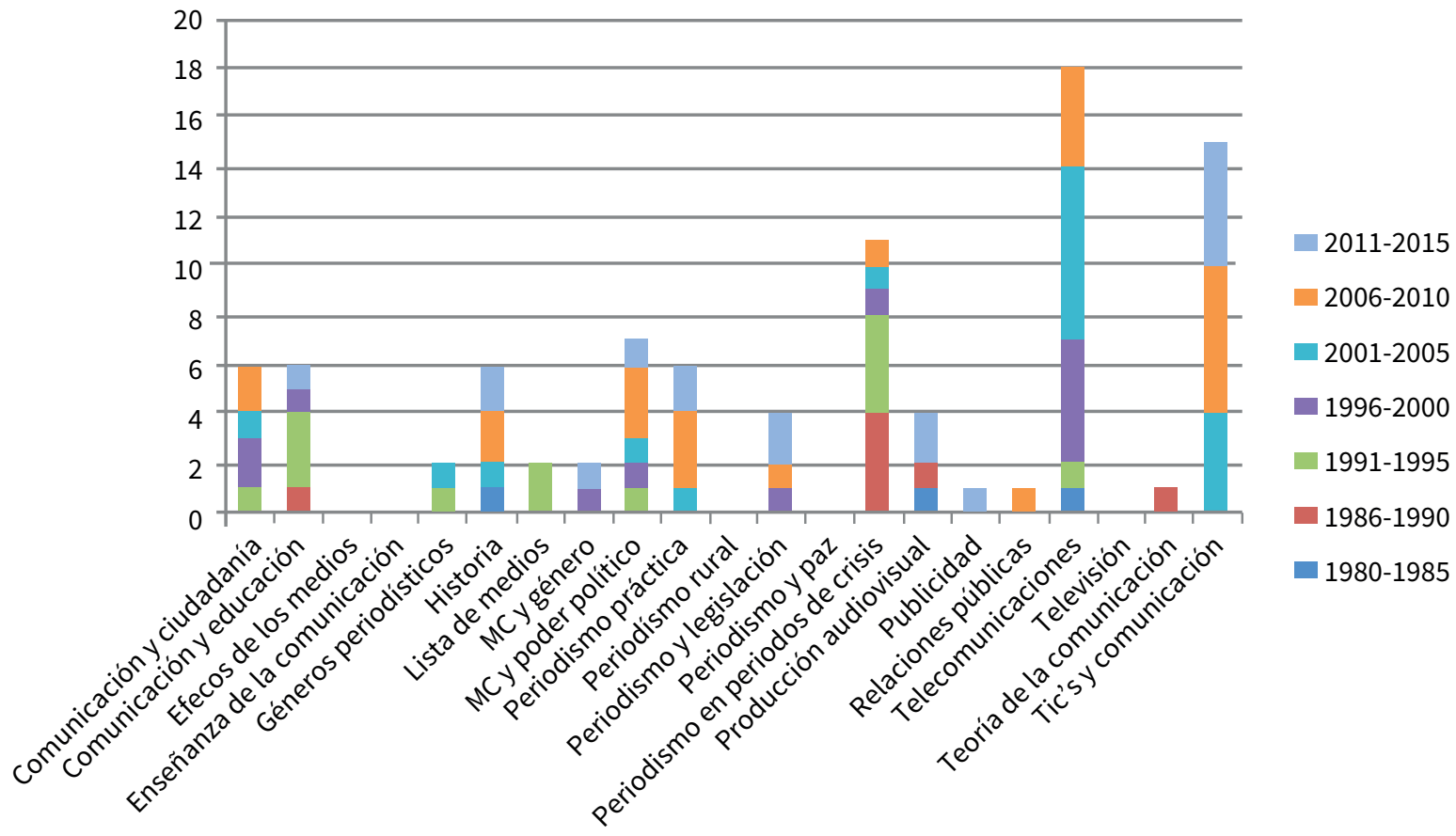

Fuente: elaboración propia 


\section{DISERTACIONES}

ESTUDIOS

Anuario electrónico de estudios en Comunicación Social

ISSN: 1856-9536

Doi: dx.doi.org/10.12804/disertaciones.09.02.2016.06

Volumen 9, Número 2 / julio-diciembre 2016

Versión PDF para imprimir desde

http://revistas.urosario.edu.co/index.php/disertaciones

Las publicaciones referentes a Nicaragua, como expone la figura 7, tienen en los últimos años una inclinación por las tecnologías y las telecomunicaciones, pero el periodismo en periodo de crisis ha ocupado a estudiosos de la comunicación, en particular, porque, como se ha expuesto, se trata de un país con vaivenes políticos frecuentes. Además, el asunto de los migrantes y la preocupación de las consecuencias culturales, políticas, económicas y fundamentalmente humanitarias también han provocado a investigadores e investigadoras a buscar, desde la comunicación, alternativas a un problema que afecta no solo a la región sino también al mundo entero.

\subsection{Panamá}

Panamá, por su condición ístmica y su trayectoria histórica, muy marcada por la construcción del Canal, tiene una dinámica muy particular. Como se ha señalado, su apuesta por el neoliberalismo justifica la cantidad de trabajos académicos que tienen como eje central el estudio de las telecomunicaciones y su vinculación con el desarrollo económico (figura 8).

Figura 8. Distribución de los textos académicos referentes a Panamá por periodos

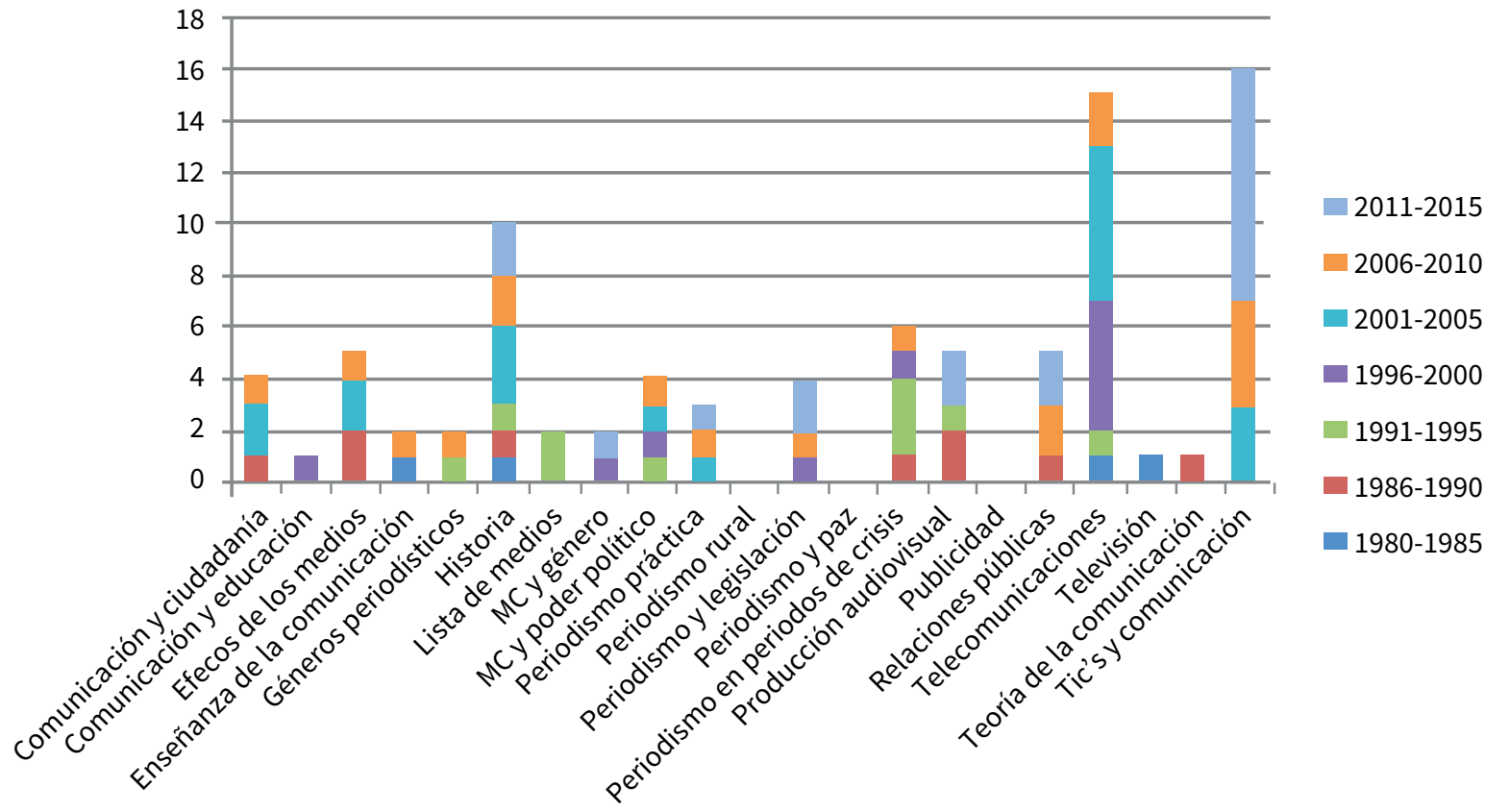

Fuente: elaboración propia.

La carrera de periodismo se inicia en 1984 en la Universidad de Panamá, pero pocas investigaciones emanan de los centros de enseñanza superior, la mayoría son hechos por organismos internacionales o por académicos que laboran fuera de Panamá. Buena parte de los textos académicos que analizan solo ese país, se refieren a historia de la comunicación (6), las Tecnologías de la Información y la Comunicación y la producción audiovisual. 


\section{DISERTACIONES}

Estudios

Anuario electrónico de estudios en Comunicación Socia

ISSN: $1856-9536$

Doi: dx.doi.org/10.12804/disertaciones.09.02.2016.06

Volumen 9, Número 2 / julio-diciembre 2016

Versión PDF para imprimir desde

http://revistas.urosario.edu.co/index.php/disertaciones

A diferencia de Honduras, El Salvador, Nicaragua y Guatemala, Panamá no sufrió la guerra en su territorio. La invasión estadounidense del 28 de noviembre de 1989 no provocó reacción entre los estudiosos de la comunicación. De hecho, el modelo neoliberal ha conducido a que Panamá sea considerado el segundo país más competitivo de América Latina según el Foro Económico Mundial ${ }^{19}$ y el país latinoamericano con mayor crecimiento económico.

\section{Conclusión}

Las investigaciones referentes a la comunicación en Centroamérica son reflexiones condicionadas por los diversos contextos y coyunturas de los países. Esto conduce a que se trate de estudios muy diferentes con una gama temática muy amplia. Esto también cambia con el tiempo. Lo que resulta evidente es que los académicos provienen de los centros de enseñanza superior, especialmente de universidades públicas en Costa Rica y de universidades privadas en Guatemala, El Salvador y Nicaragua.

Las Escuelas de comunicación son tardías en Honduras, Panamá y Nicaragua. No obstante, los textos que analizan las comunicaciones en esos países no están ausentes en los años previos al establecimiento de las escuelas de comunicación. Esto se debe a que hay una tendencia creciente por realizar análisis comparativos y/o regionales. Tanto los organismos internacionales, cuanto los y las académicas prefieren realizar investigaciones que involucren a la región y no solo a sus países de origen. El compromiso de la academia con la sociedad y la política se evidencia en la proliferación de trabajos referentes a la comunicación en periodos de crisis justo cuando la región sufre el conflicto que aun no acaba.

Las propuestas teóricas por las que abogan los y las investigadoras para sustentar sus trabajos son las que están en apogeo en el momento del estudio. Así, por ejemplo, en las décadas de 1980 y 1990 se privilegia la teoría de la dependencia. Tras el fin de la Guerra Fría se suman a las teorías funcionalistas y la Escuela de Fráncfort, la economía política y los estudios culturales, o combinaciones entre estas. Definitivamente, no hay una defensa a ultranza de una u otra. Esto se debe a que a partir del segundo quinquenio de 1980 profesionales de la comunicación y de otras disciplinas realizan estudios doctorales vinculados con la comunicación en Universidades de Europa, América Latina y Estados Unidos. Estos académicos se incorporan al profesorado y realizan investigaciones en torno a la comunicación siguiendo los conocimientos adquiridos. La convergencia de diversas escuelas de pensamiento enriquece la producción académica. Paralelamente, se evidencian cambios fundamentales en la apertura de los estudios de la comunicación desde una perspectiva inter- y transdisciplinaria, lo que ha favorecido "la construcción de un diálogo articulado y de mediaciones que hacen y marcan precisamente su especificidad y reubican a la comunicación en el ámbito más amplio de las ciencias sociales” (León, 2002, p. 19).

El neoliberalismo permea los estudios de comunicación y conduce a la vinculación del mercado y el lucro por medio de las tecnologías. Lleva razón Martín Barbero (1980) al sostener que las tecnologías de la información y la comunicación están seriamente amarradas a una concepción instrumentalista de la técnica y el peso histórico y el entramado político.

El camino apenas inicia. Las posibilidades de investigación en comunicación se amplían con diversos retos y problemáticas que requieren de la atención de las y los académicos en procura de buscar solución a los múltiples problemas que afectan la región. 


\section{DISERTACIONES}

ESTUDIOS

Anuario electrónico de estudios en Comunicación Social

ISSN: $1856-9536$

Doi: dx.doi.org/10.12804/disertaciones.09.02.2016.06

Volumen 9, Número 2 / julio-diciembre 2016

Versión PDF para imprimir desde

\section{Referencias}

1. Agulló, C. (2014). Otras situaciones de violencia en el triángulo del Norte Centroamericano, Impacto Humanitario, mayo 2014. Madrid: Instituto de Estudios sobre Conflictos y Acción Humanitaria. Recuperado de http://www.iecah.org/index.php/boletiniecah/resenas/2560-otras-situaciones-de-violencia-en-el-triangulo-del-norte-centroamericano-impacto-humanitario-mayo-2014

2. Castañeda, M., \& Morales, Y. (2011). La teoría desarrollista de Raúl Prebisch y la política de industrialización de América Latina. Recuperado de: http://www.docfoc.com/la-teoria-desarrollista-de-raul-prebisch-y-la-politica-de-industrializacion

3. Cinco (s.f.). ¿Qué es cinco? Recuperado de http://cinco.org.ni/es/que-es-cinco.

4. Esteinou, J. (julio-septiembre, 1998). La investigación de la comunicación en tiempos neoliberales. Razón y Palabra, 11(3). Recuperado de http://www.razonypalabra.org.mx/anteriores/n11/esten11.html

5. Fuentes, R. (1999). La investigación de la comunicación en América Latina: Condiciones y perspectivas para el siglo xx. Ponencia presentada en el Seminario internacional: Tendencias y retos de la investigación en comunicación en América Latina. Pontificia Universidad Católica de Perú/felafacs, Lima, Perú.

6. Human Rights Watch (2015). Informe Mundial 2015: Honduras. Recuperado de https://www.hrw.org/es/ world-report/2015/country-chapters/268141

7. León, G. (2001). Teorías e Investigación de la Comunicación en América Latina. Situación Actual. Ámbitos, 7-8, 19-47.

8. Martín-Barbero, J. (1980). Retos a la investigación de comunicación en América Latina. Recuperado de http://www.perio.unlp.edu.ar/catedras/system/files/barbero_martin_retos_a_la_investigacion_en_la_ comunicacion_en_a.l..pdf

9. Trejos, E. (2012). Apertura de las telecomunicaciones. 5 años de avances y desafíos. PRosic, VII Informe Hacia la Sociedad de la Información y el Conocimiento 2012 San José: Editorial de la Universidad de Costa Rica.

10. Universidad Centroamericana José Simeón Cañas (s.f.). Los asesinatos y sus consecuencias. Recuperado de http://www.uca.edu.sv/pagina-web.php?cat=9\&pag=7)

11. Vega, P. (2012). ¿Libertad de expresión en Centroamérica? En P. Vega (ed.), Desafíos de la Comunicación Social (pp. 207-240). San José: Editorial de la Universidad de Costa Rica.

12. Vega, P. (2013). Investigando la comunicación en Centroamérica. Ponencia presentada en ॥ Congreso Nacional de Metodología de la Investigación en Comunicación, Segovia, España. 